\title{
TRANSITION IN ENDOCRINOLOGY Induction of puberty
}

\section{Leo Dunkel and Richard Quinton ${ }^{\mathbf{1}}$}

Barts and the London, Queen Mary College, William Harvey Research Institute, Centre for Endocrinology, University of London, Charterhouse Square, London EC1M 6BQ, UK and ${ }^{1}$ Endocrinology Research Group, Institute of Genetic Medicine, University of Newcastle-upon-Tyne, Times Square, Newcastle NE1 3BZ, UK
Correspondence should be addressed to R Quinton

Email

richard.quinton@ncl.ac.uk

\begin{abstract}
Puberty is the period during which we attain adult secondary sexual characteristics and reproductive capability. Its onset depends upon reactivation of pulsative $\mathrm{GNRH}$, secretion from its relative quiescence during childhood, on the background of intact potential for pituitary-gonadal function. This review is intended: to highlight those current practices in diagnosis and management that are evidence based and those that are not; to help clinicians deal with areas of uncertainty with reference to physiologic first principles; by sign-posting relevant data arising from other patient groups with shared issues; to illustrate how recent scientific advances are (or should be) altering clinician perceptions of pubertal delay; and finally, to emphasise that the management of men and women presenting in advanced adult life with absent puberty cannot simply be extrapolated from paediatric practice. There is a broad spectrum of pubertal timing that varies among different populations, separated in time and space. Delayed puberty usually represents an extreme of the normal, a developmental pattern referred to as constitutional delay of growth and puberty (CDGP), but organic defects of the hypothalamo-pituitary-gonadal axis predisposing to hypogonadism may not always be initially distinguishable from it. CDGP and organic, or congenital hypogonadotrophic hypogonadism are both significantly more common in boys than girls. Moreover, around $1 / 3$ of adults with organic hypogonadotrophic hypogonadism had evidence of partial puberty at presentation and, confusingly, some $5-10 \%$ of these subsequently may exhibit recovery of endogenous gonadotrophin secretion, including men with Kallmann syndrome. However, the distinction is crucial as expectative ('watch-and-wait') management is inappropriate in the context of hypogonadism. The probability of pubertal delay being caused by organic hypogonadism rises exponentially both with increasing age at presentation and the presence of associated 'red flag' clinical features. These 'red flags' comprise findings indicating lack of prior 'mini-puberty' (such as cryptorchidism or micropenis), or the presence of non-reproductive congenital defects known to be associated with specific hypogonadal syndromes, e.g. anosmia, deafness, mirror movements, renal agenesis, dental/digital anomalies, clefting or coloboma would be compatible with Kallmann (or perhaps CHARGE) syndrome. In children, interventions (whether in the form or treatment or simple reassurance) have been historically
\end{abstract}

Invited Authors' profile:

Dr Richard Quinton graduated in medicine from the University of Cambridge, which awarded him an entrance exhibition in 1983 and the Ralph Noble Prize for his MD thesis on Kallmann's. He was appointed Consultant Endocrinologist at the Royal Victoria Infirmary and Senior Lecturer at the University of Newcastle-upon-Tyne, where he is a full member of the Institute of Genetic Medicine. He is Vice Chair of the EU-funded COST consortium on diseases affecting the neuroendocrine control of human reproduction and is the UK representative to the Endocrine Section of the European association of Medical Specialists (UEMS).

Professor Leo Dunkel worked at the University of Kuopio as Chair of Paediatrics, Department of Clinical Medicine, University of Kuopio, Finland. In 2012, he was appointed, alongside Professor Marta Korbonits, the Centre Lead for Endocrinology, School of Medicine and Dentistry, Queen Mary University of London. Professor Dunkel has served on the Editorial Boards of many prestigious peer-reviewed journals. He is also a Member of the EU-funded COST consortium (BM1105) on diseases affecting the neuroendocrine control of human reproduction (www.gnrhnetwork.eu).

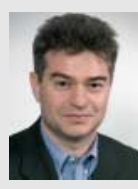

(C) 2014 European Society of Endocrinology Printed in Great Britain
Published by Bioscientifica Ltd. 
directed at maximising height potential and minimising psychosocial morbidity, though issues of future fertility and bone density potential are now increasingly 'in the mix'. Apubertal adults almost invariably harbour organic hypogonadism, requiring sensitive acknowledgement of underlying personal issues and the timely introduction of sex hormone replacement therapy at more physiological doses.

\section{Introduction}

Puberty is a period during which children attain adult secondary sexual characteristics and reproductive capability. The onset of puberty requires an intact hypothalamic-pituitary-gonadal (HPG) axis. Reactivation of the secretion of gonadotrophin-releasing hormone (GNRH) from its stage of childhood quiescence stimulates luteinising hormone $(\mathrm{LH})$ and follicle-stimulating hormone (FSH) secretion, which in turn activates the production of gonadal sex steroids.

The first external sign of puberty in girls is usually the initiation of breast development, designated as change from Tanner stage B1 to B2 (B2; also called breast budding) and, in boys, change from Tanner's genital stage G1 to G2 including enlargement of the testes (i.e. achievement of volume $>3 \mathrm{ml}$ or testicular length $\geq 25 \mathrm{~mm})(1,2,3,4)$. Development of pubic hair is usually not regarded as a marker for pubertal onset because pubarche may result from maturation of the adrenal glands (adrenarche) and onset of pubic hair can thus be independent of HPG axis activation.

There are clear differences in pubertal timing among ethnic groups, but in most populations the average ages at attainment of the first signs of puberty are around ten for girls and 12 in boys $(5,6)$. Puberty is delayed if there is no breast development by 13 years in girls or absence of testicular enlargement by 14 years in boys (4). Because of the secular change towards earlier onset of puberty in the USA $(7,8)$ and some other countries $(5,6)$, different age limits may be more appropriate in some ethnic groups. Even the latest-developing girls seem to start their puberty 1 year earlier than two decades ago $(5,6)$.

\section{Evaluation of delayed puberty}

Constitutional delay of growth and puberty (CDGP) represents the commonest cause of delayed puberty in both sexes. At least $30 \%$ of girls and up to $65 \%$ of boys with delayed puberty have CDGP (9). Autosomal dominant mode of inheritance (with or without complete penetrance) is the commonest inheritance pattern (10). Although CDGP does seem to be more frequent than might be expected among first-degree relatives of probands with hypogonadotrophic hypogonadism, the genetic basis of this observation remains elusive. In the study population, $50-75 \%$ of subjects with CDGP have a family history of delayed puberty. As much as $80 \%$ of all variation in the timing of puberty is due to genetic factors $(11,12)$.

CDGP can be considered an extreme of the normal spectrum of pubertal timing, but can be diagnosed only after exclusion of other underlying conditions. The differential diagnosis of CDGP is divided into three main categories $(4,9)$ : hypergonadotrophic hypogonadism (characterised by elevated gonadotrophin levels due to lack of negative feedback from the gonads), congenital hypogonadotrophic hypogonadism (CHH-characterised by low LH and FSH levels due to organic hypothalamic or pituitary disorders) and transient (or functional) hypogonadotrophic hypogonadism $(\mathrm{FHH})$, where pubertal delay is due to maturational delay in the HPG axis secondary to an underlying non-reproductive condition.

One of the most difficult distinctions is that between CDGP and $\mathrm{CHH}$ in teenage years. Subjects with CDGP are typically short, because their skeletal maturation is delayed and their height is compatible with the bone age. In about half of adolescents with CDGP, linear growth has already begun to falter in the years before the expected onset of puberty, and it has been shown that these children with poor growth in childhood do not fully exploit their genetic height potential and will ultimately have adult height significantly below their mid-parental target height (13). By contrast, patients with $\mathrm{CHH}$ have steady linear growth during childhood and only become short for their age with absence of the pubertal growth spurt. In a typical case, the diagnosis of $\mathrm{CHH}$ is made during the second or third decade of life, but the diagnosis is sometimes only made much later in life. Common presenting signs are delayed onset of puberty, primary amenorrhoea, 
poorly developed secondary sexual characteristics, eunuchoid body proportions, or infertility, though the diagnosis can sometimes be suspected before the age of pubertal onset (indeed, in the first 6 months of life it can actually be confirmed on the basis of low testosterone and gonadotrophin levels). This is a crucial distinction as expectative ('watch-and-wait') management is inappropriate in the context of teenage $\mathrm{CHH}$. For the differential diagnosis of the two conditions, a variety of physiological and stimulation tests have been proposed, such as assessment of LH pulsatility by frequent sampling (14), prolactin response to various provocations (15), gonadotrophin response to GNRH (16), testosterone response to human chorionic gonadotrophin (hCG) $(17,18,19)$ and first morning-voided urine FSH and LH (20). Most recently, a single measurement of inhibin B level has been shown to discriminate complete $\mathrm{CHH}$ from CDGP with specificity of $100 \%$ at inhibin B concentration of $35 \mathrm{pg} / \mathrm{ml}$ in pre-pubertal boys (21). However, the presence or absence of 'red flag' features remains the strongest differentiator. These 'red flags' comprise findings indicating lack of prior 'mini-puberty' (such as cryptorchidism or micropenis), or the presence of non-reproductive congenital defects known to be associated with specific hypogonadal syndromes, e.g. anosmia, deafness, mirror movements, renal agenesis, dental/digital anomalies, clefting or coloboma would be compatible with Kallmann syndrome (KS), or conceivably CHARGE syndrome. Nevertheless, around $1 / 3$ of adults with organic hypogonadotropic hypogonadism have evidence of partial puberty at presentation, with correspondingly higher levels of Inhibin B. Moreover, some $5-10 \%$ of $\mathrm{CHH}$ men may subsequently exhibit recovery of endogenous gonadotropin secretion, including some with KS $(22,23)$.

In adults, the diagnostic value of the GNRH test is limited (24) and assessment of baseline gonadotrophin levels is usually sufficient. Similarly, other hormones of the pituitary should be first evaluated by basal hormonal levels (measured by ultrasensitive assays), with provocation tests reserved for situations in which the basal hormone measurements are insufficiently informative, or in cases where there is strong clinical evidence of a multiple pituitary hormone deficiency.

Anosmia can often be diagnosed by simply asking the patient, but only semi-quantitative olfactometry (e.g. UPSIT) (25) can reliably distinguish between normal or partially defective olfaction. Accurate olfactory phenotyping can support more directed genetic testing (26). Magnetic resonance imaging (MRI) of the olfactory tract (especially $\mathrm{T} 2$-weighted coronal views) can readily demonstrate hypoplastic or absent olfactory bulbs, which are pathognomonic of KS. MRI should also be used in suspicion of pituitary and/or hypothalamic tumours, in patients with persistent hyperprolactinaemia, multiple pituitary hormone deficiency or neurological signs of a tumour clinical (visual field defects and headache). However, according to a recent clinical practice guideline, the cost effectiveness of MRI to exclude pituitary and/or hypothalamic tumours has not been established (27). In contrast, MRI is seldom indicated for suspected FHH. We also recommend assessment of bone mineral density of the lumbar spine, femoral neck and hip at the initial diagnosis of $\mathrm{HH}$ and after 1-3 years of sex steroid therapy in hypogonadal patients (though if resources limit the number of scans, then obviously the key time point at which to scan would be after the first few years of treatment).

At present, several things limit our ability to integrate genetic mutational analysis into everyday clinical practice. First, our knowledge of the spectrum of genes involved is incomplete. Second, so is our knowledge of adult phenotypes associated even with sequence variants of known genes. Third, the timelines for turnaround of genetic data from research labs are generally longer than clinicians have available to make decisions. However, there are circumstances where clinical genetics can play a key role, such as where there is already a known high-penetrance genetic variant (e.g. KAL1 and FGFR1) segregating within a given kindred.

Another diagnostic challenge with slim gonadotrophin-deficient women is that between organic $\mathrm{CHH}$ and functional hypothalamic amenorrhoea (HA), relating to bioenergetic stress and/or occult underlying nongonadal disease. Indeed, with particularly severe stress, gonadotrophin levels can even become suppressed in women with primary ovarian failure. Pragmatically, however, the endocrine aspects to treatment are the same (oestrogen for induction/maintenance of post-adrenarchial secondary sexual characteristics and bone health; ovulation induction with gonadotrophin for infertility). Moreover, there is now known to be genetic overlap between organic and functional gonadotrophin deficiency syndromes, such that HA is now more usefully considered as resulting from genetic-environmental interactions (28).

\section{Considerations in different diagnostic groups}

Induction of puberty is commonly considered for adolescents who either have delayed puberty or have been 
Table 1 Common causes of delayed puberty other than constitutional delay of growth and puberty. Table modified and reprinted with permission from Palmert et al. (6).

\section{Hypergonadotrophic hypogonadism}

Common causes:

Turner syndrome

Gonadal dysgenesis

Chemotherapy/radiation therapy

\section{Hypogonadotrophic hypogonadism}

CNS tumours/infiltrative diseases

Isolated hypogonadotrophic hypogonadism

Kallmann syndrome

Combined pituitary hormone deficiency

Chemotherapy/radiation therapy
Functional hypogonadotrophic

hypogonadism

Systemic illness/conditions

Inflammatory bowel disease

Celiac disease

Anorexia nervosa/bulimia

Hypothyroidism

Excessive exercise diagnosed with hypogonadism. Appropriate treatment modalities vary by the diagnosis. Commonest causes of hypogonadism causing delayed puberty are listed in Table 1.

For men and women presenting with absent or partial puberty and biochemical hypogonadotrophic hypogonadism beyond the teenage years, the diagnostics and treatment aims are straightforward. CDGP is no longer a likely diagnosis and, as these individuals have generally already attained normal adult stature, this i) makes it improbable that they should harbour broader hypopituitarism beyond isolated gonadotrophin deficiency (though serum screening for hyperprolactinaemia, iron overload and, possibly, coeliac disease is essential) and ii) removes any potential therapeutic conflicts between the goals of maximising final height and promptness of pubertal induction. Sex hormone replacement in hitherto apubertal adults can result in dramatic improvements in bone density, even when this treatment has only been initiated in middle age.

The reasons for highly delayed presentations beyond the teenage years in some patients with $\mathrm{CHH} / \mathrm{KS}$ have not been subject to any formal analysis, but recurrent themes emerge from both physician personal experience, and from patient experiences shared at focus groups and/or in online electronic traffic on the various support group-hosted sites. These include general shyness (of patient and/or parents), constitutional reluctance or financial constraints inhibiting engagement with healthcare systems, strongly held beliefs expressed by friends, family or physicians that 'everything will be alright in the end' and, frankly, overt errors of omission or procrastination made by physicians they encountered in earlier life. The association of pubertal delay with a history of any reproductive or non-reproductive defect associated with 'red flag markers' of permanent hypogonadism (micropenis, cryptorchidism, anosmia, deafness, clefting, etc.) should be a diagnostic 'game changer', but all too often is not (29). Some patients have pointed to intensive and, perhaps, overenthusiastic investigation at their initial presentation as having induced them to miss follow-up visits and disengage with endocrine follow-up for many years thereafter. Patients from cultures favouring arranged marriage and/or 'modesty' in clothing coverage can also occasionally remain undiagnosed until the outcome of infertility investigations. The case histories contained in the online supplementary data from Santhakumar et al. (2013) illustrate most of these issues (30).

In CDGP, where pubertal delay is transient, the patient should make the decision regarding whether the treatment is initiated, but if there are 'red flag' markers of permanent hypogonadism there is no reason to defer treatment; the goal of such therapy is to accelerate growth and/or to induce secondary sexual characteristics and, potentially, to alleviate psychosocial difficulties. Late puberty can affect psychosocial well-being and, as late-developing adolescents are often short compared with their peers, patients and families are often concerned that delayed puberty may also affect adult stature. Many adolescents present with delayed puberty combined with relative familial short stature, compounding these concerns and leading to more subspeciality referrals than would either condition alone; however, adult height only slightly below the genetic height potential (target height) is usually reached (31). If stature is not a major concern, reassurance with accurate adult height prediction is frequently sufficient, especially if puberty has already started. Hormonal therapy can be beneficial, especially for those who have decreased selfesteem, if there is clear anxiety about growth rate and/or delayed pubertal characteristics, or if there are psychosocial difficulties that may derive from negative interactions with peers $(32,33,34,35)$.

If endogenous gonadotrophin-dependent puberty has not started after 1 year of treatment, then permanent hypogonadotrophic hypogonadism and other diagnoses should be reconsidered and an MRI of the brain is indicated.

For the treatment of ovarian failure in girls with Turner syndrome, there is significant uncertainty about 
the appropriate timing and dosage for oestrogen-replacement therapy $(30,36,37)$. Elevated gonadotrophin levels and slow skeletal maturation suggest that oestrogen deficiency in Turner girls begins already in infancy $(38,39)$. Oestrogen may also have positive behavioural and neurocognitive effects in the developing brain $(40,41)$. Despite this evidence, until recently a common clinical practice has been to postpone oestrogen-replacement therapy until the mid-teens. This practice was based on the widely held view that too-early onset of oestrogen therapy might reduce adult height by accelerating epiphyseal fusion (42). This view has been revised by studies showing that postponing oestrogen replacement in adolescent girls with Turner syndrome may compromise selfesteem and social adjustment and does not provide any beneficial effect on adult height (37). Indeed, recent data from a placebo-controlled study suggest that combining ultra-low doses of ethinyl oestradiol (EE; as low as $25 \mathrm{ng} / \mathrm{kg}$ daily for children from 5.0 to 8.0 years of age; $50 \mathrm{ng} / \mathrm{kg}$ daily for those aged 8.0-12.0 years of age) with growth hormone $(\mathrm{GH})$, may improve growth and provide other potential benefits (ClinicalTrials.gov number, NCT00001221) (43). Obviously, this study would bear repeating using tiny doses of $17 \beta$-oestradiol, given the illogicality inherent in using $\mathrm{EE}$ as 'oestrogen replacement' for patients on $\mathrm{GH}$ (q.v.). Moreover, there are also data linking a history of late introduction of oestrogen therapy with incomplete uterine maturation in adult Turner women, which could impact adversely on egg-donation outcomes (44).

\section{How to treat}

\section{Constitutional delay of growth and puberty}

The options for management of CDGP include expectant observation or therapy with low dose testosterone (in boys) or oestrogen (in girls) (Table 2). Numerous studies of treatment of CDGP in boys have been reported. These are largely observational and some randomised-controlled trials (carried out with small numbers of subjects), which involve low doses of androgens given in short courses $(31,33,35)$. Such therapy expedites growth but does not advance bone age over calendar age, advances sexual maturation and often improves psychosocial well-being. For girls, similar outcomes are likely although published data are scarce. For girls, therapy is initiated with appropriately low doses of oestrogen (Table 2). CDGP is an overlapping condition with idiopathic short stature (ISS) and, for a subset of patients, short stature can be more concerning than delayed puberty. Although the US FDA has approved GH for the treatment of ISS and height SDS $\leq 2.25$ for age, this therapy increases adult height only modestly in CDGP and its use is not recommended.

In short boys with CDGP, another potential therapeutic approach is the inhibition of oestrogen biosynthesis with aromatase inhibitors (AIs) $(45,46)$. AIs inhibit conversion of androgens to oestrogens, and because oestrogen is the predominant hormone needed for epiphyseal closure, AIs could prolong growth in height and thus potentially increase final adult height. In boys with short stature and/or delayed puberty, AIs are reported to delay bone maturation and appear to increase adult height in controlled trials $(45,46)$. However, the treatment efficacy in centimetres gained as well as the optimal dose, timing and duration of treatment remain uncertain. In particular, typical doses used for the treatment of ER + breast cancers are almost certainly far too high for this putative indication. Moreover, potential adverse effects, especially impaired trabecular bone development and vertebral body deformities observed in boys with ISS treated with letrozole (47), must also be considered. Pending the outcome of ongoing clinical trials of these agents, therapy should be with testosterone alone unless stature is an overwhelming concern. We do not use GH or anabolic steroids, and believe that AIs are most appropriately used within clinical trials for the present time.

For boys with CDGP who elect to be treated, we initiate supplementation with $50 \mathrm{mg}$ testosterone ester i.m. each month for 3-6 months, which can be repeated for another 3-6 months with dose escalation (Table 2).

For girls, we prefer oral or transdermal $17 \beta$-oestradiol for several reasons. First, it is a precautionary principle to replace any given endocrine deficiency with the bioidentical hormone, whenever practical. Second, data from hypopituitary females receiving combined oestrogen and GH treatment indicate a markedly greater impairment of GH-mediated insulin-like growth factor 1 (IGF1) synthesis with EE than with $17 \beta$-oestradiol (48), with a smaller inhibitory effect observed by taking $17 \beta$-oestradiol transdermally vs orally (49). Finally, data from UK and Dutch registries of trans-women (male-to-female transsexuals) have highlighted a much greater risk of venous and/or arterial thrombosis with $\mathrm{EE}$ and conjugated equine oestrogens than with $17 \beta$-oestradiol $(50,51,52)$. Given that linear growth is an intrinsic concern in CDGP, it seems both unwise and unnecessary (despite longstanding habit and custom) to expose young girls to a synthetic molecule, with demonstrably higher thrombosis risk and the theoretical potential for growth impairment, when there is a better alternative. 


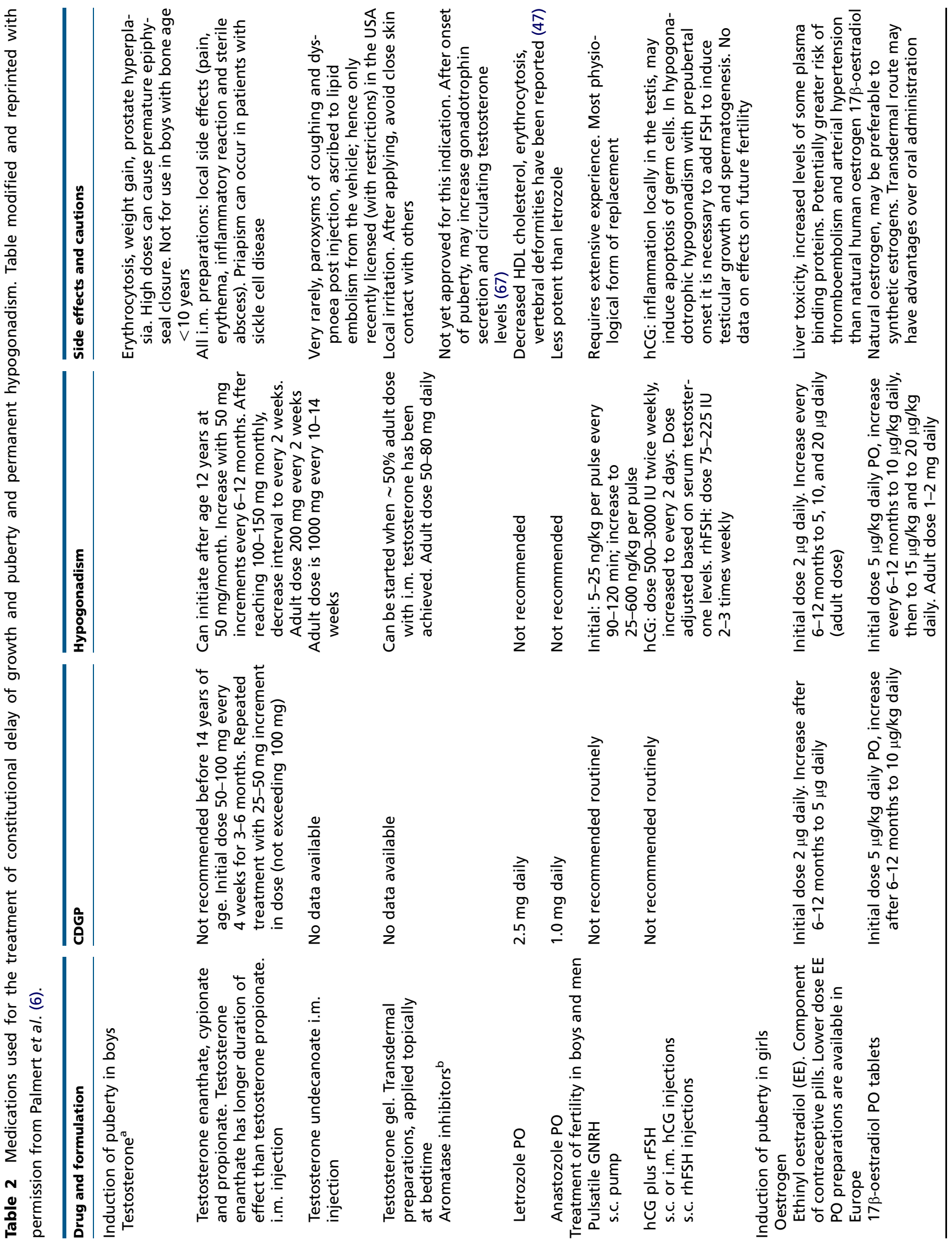



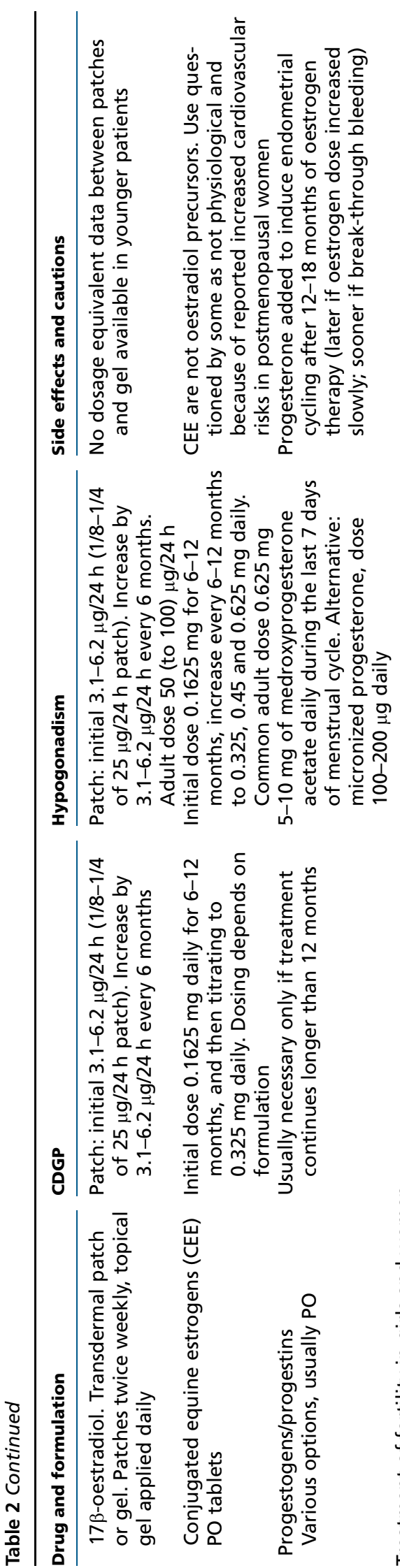

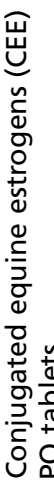

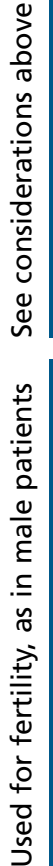

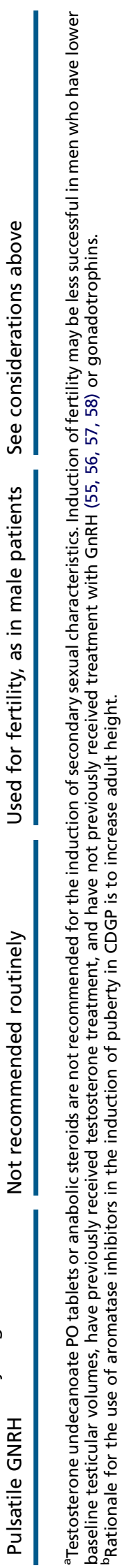

When deciding whether to use oral or transdermal $17 \beta$-oestradiol, the following factors should be considered. First, beyond the potential for better GH-mediated IGF1 synthesis, data from postmenopausal women suggest other advantages of the transdermal route in avoiding hepatic first-pass metabolism, both in respect of potentially lower thrombogenicity (53) and more neutral effect on lipids, with oral oestrogens tending to lower LDL-cholesterol and raise triglycerides (54). Second, it is usually easier to administer tiny doses of $17 \beta$-oestradiol by cutting up a matrix patch or by using a metered-dose gel dispenser, than it is to split tablets. However, patient acceptability and product preference are crucial and, before getting too fixated on the minutiae of dosimetry, the huge individual variability in drug absorption needs to be recognised. Roughly speaking, similar plasma levels are achieved using $2 \mathrm{mg}$ daily oral $17 \beta$ oestradiol, $2 \mathrm{mg}$ daily gel and $100 \mu \mathrm{g}$ patch, but with up to tenfold differences in $17 \beta$-oestradiol levels between individual patients using the same preparation (e.g. (49)).

\section{Hypogonadotrophic hypogonadism}

In boys and girls with $\mathrm{HH}$, initial sex steroid therapy is the same as for CDGP (indeed the two diagnoses may not always be initially distinguishable), but doses are gradually increased to full adult replacement levels over $\sim 3$ years (Table 2). Exogenous testosterone does not induce testicular growth or spermatogenesis in men with hypogonadotrophic hypogonadism. Equally, exogenous oestrogen does not induce ovulation (findings that clinch the diagnosis), and induction of fertility in both sexes requires treatment with either pulsatile $\operatorname{GNRH}(55,56,57)$ or exogenous gonadotrophins (57). Fertility outcomes with each regimen are variable, with poorer responses in patients with signs of absent mini-puberty (prepubertal testes, cryptorchidism and/or low IB) $(56,58)$.

Induction of puberty in adolescent males with either hCG monotherapy or with combinational therapy of hCG + recombinant FSH (rFSH) may result in better testicular growth and improvement in potential fertility compared with treatment with testosterone therapy (59). If the patient has spontaneous onset of pubertal development one can start with hCG monotherapy; FSH can be added in cases where azoospermia persists after 6-12 months of treatment. Early induction of spermatogenesis may increase sperm production capacity and reduce the time required for appearance of sperm once fertility is desired. Monotherapy of hCG alone is at least theoretically less efficacious in the induction of spermatogenesis induction than combinational therapy of hCG + FSH $(59,60)$. 
The optimal regimen to maximise the potentiality for fertility in severe cases, i.e. those with testicular volume $<4 \mathrm{ml}$, is unknown. FSH pretreatment may plausibly maximise the Sertoli cell population before exposure to hCG or GNRH-induced endogenous LH and thus has the potential to improve fertility outcomes (61). In girls with $\mathrm{HH}$, treatment with oestrogen needs to be combined with progestin for endometrial cycling.

For older men and women presenting with IHH, pharmacologic treatment is potentially much simpler, though psychological support is a frequently unmet need that is only partly compensated for by help available from patient support groups. The only factors limiting the tempo and dosimetry of pubertal induction in men are the absolute requirements to avoid erythrocytosis and psychological destabilisation related to a late coming-to-terms with issues of libido and sexuality. Given that these patients delayed their presentations for so long, it may seem counter-intuitive that they should wish to 'get it all over with as soon and as simply as possible', but that is a commonly expressed wish, and they can easily become frustrated and disappointed with the apparent slowness of their progress on 'paediatric' doses of testosterone. A regime comprising stepwise incremental doses of testosterone gel via calibrated dispenser would appear to offer the best possibility of achieving physiological simulation of male puberty. However, when offered the choice, our older apubertal men have almost universally chosen a less physiological, but for them much simpler regime, of 4 monthly i.m. depot injections of testosterone undecanoate $1 \mathrm{~g}$, leading to full pubertal development after around 1 year, without any apparent excursions of haematocrit, or reported psychological difficulties or 'drop-outs' (62). Given the lack of an observed 'andropause' in normal men and the huge degree of overlap between the adverse consequences of untreated hypogonadism and those of normal male ageing (sarcopaenia, osteopaenia, anaemia, etc.), there is no plausible upper age limit beyond which pubertal induction should not generally be undertaken.

For older hypogonadal women, the factors limiting the tempo and dosimetry of oestrogen replacement are the need to optimise breast development and to minimise sensations of bloating and/or breast discomfort that can arise on initial exposure. These women may already have severe osteoporosis and/or sustained a low-trauma fracture, but we would encourage physicians not to reflexly initiate antiresorptive therapy with bisphosphonate right at the outset. These agents lack an evidence base in women (and men) who are totally naive to sex hormones and, moreover, also lack adequate safety and efficacy data much beyond
5-10 years anyway. So bisphosphonates are ideally kept in reserve for later life when discontinuation of oestrogen/ progestogen replacement is being contemplated.

Unlike the careful dose titration typically carried out for hypogonadal men, oestrogen/progestogen replacement therapy in adult women has traditionally been entirely empirical, based upon the capacity of a preparation to induce withdrawal bleeds (short-term signal) or to improve/maintain bone density on serial DEXA scanning (ultra long-term signal). This is another area where the optimal management of hypogonadal women might usefully be informed by patient registry data held in relation to trans-women, for whom therapy titrated to achieve serum oestradiol levels in the $300-400 \mathrm{pmol} / \mathrm{l}$ range seems to give the best trade-off between benefits and risks (51). In women with impaired bone density at baseline, it is logical to defer bone-directed antiresorptive therapies at least until after maximum anabolic effect of oestrogen on bone has been achieved, as ascertained by serial DEXA scans. There are no data to inform an evidencebased decision on when to stop sex hormone replacement in a hypogonadal woman. However, if bone density is an issue (which it usually is), then it is logical to continue replacement therapy at least until the upper end of the age range for normal age at menopause.

\section{Male hypergonadotrophic hypogonadism}

Klinefelter syndrome is by far the commonest $(0.1-0.2 \%$ birth prevalence) cause of hypergonadotrophic hypogonadism in males and comprises a wide spectrum of clinical and biochemical severity. Nevertheless, as virtually all affected boys manage to initiate puberty, the clinical picture of partial puberty that may be evident in later life may reflect secondary regression effect, more than primary failure of attainment. Only a minority of Klinefelter boys have come to the attention of an endocrinologist by the end of their teenage years, but such patients present potentially difficult management decisions in terms of optimising fertility outcomes.

These have already been extensively reviewed elsewhere $(63,64)$ but in essence relate to the following issues. First, although the techniques, success rates and general availability for testicular biopsy (or microdissection), sperm retrieval and sperm cryopreservation are continually advancing, this is counterbalanced by the rate of progressive seminiferous tubule degeneration occurring in the patients themselves. Second, the most invasive (and successful) sperm retrieval techniques have the potential to cause the most testicular damage and so would ideally be reserved 
for those men actively desiring fertility, in whom this could be combined with superovulation induction, ICSI and embryo transfer into their partners. Yet, fertility is typically not at the forefront of the minds of Klinefelter adolescents, who are at the very peak of their fertility potential then. Finally, it has been suggested that early exposure to exogenous testosterone may reduce success rates of sperm retrieval. All these factors make for difficult conversations with vulnerable young men and their parents.

Regarding the appropriate time to commence androgen replacement in men with Klinefelter syndrome, the key parameters are serum testosterone level, haematocrit, bone density, patient well-being and sexual function. Even if these remain individually within the male reference range, the accumulation of longitudinal data showing a significant rate of decline indicates that the time has come to initiate treatment.

\section{Areas of uncertainty and future research}

Studies are needed to assess what impact sex steroid supplementation has on the psychosocial distress experienced by individuals with delayed puberty, and whether this distress has long-term consequences. It is not known whether pubertal delay adversely affects adult bone mass (65) and whether potentially compromised bone health is a reason to initiate sex-steroid replacement. Different oestrogen formulations, routes of administration (oral vs transdermal) and dosing regimens should be studied in controlled trials to develop optimal therapy for girls with delayed puberty.

Other areas for further evaluation include defining the optimal therapy for males with severe hypogonadotrophic hypogonadism, characterised by cryptorchidism, micropenis and lack of spontaneous increase in testicular size in puberty. For instance, should male neonates with bilateral cryptorchidism and/or micropenis be screened for hypogonadotrophic hypogonadism, by checking testosterone and gonadotrophin levels between 1 week and 6 months after birth? With advances in our knowledge of the genetics of $\mathrm{IHH}$, we are also likely to be getting an increasing number of putative diagnoses made in pre-adolescent age, either as a result of family history or from recognition of IHH-associated clinical features (anosmia, history of cryptorchidism, etc.). Might their future fertility outcomes be enhanced by the earliest possible exposure to FSH, so as to 'catch up' on the minipuberty that they never had?

The minority of Turner girls who maintain normal ovarian function (evidenced by persistent menstrual cyclicity and normal levels of gonadotrophins and $\mathrm{AMH}$ ), but who are not in a relationship will necessarily be concerned about the possibility of early menopause. An increasing number are likely to turn to ovarian cryopreservation techniques, subject to financial constraints and local availability (66). Long-term outcome data for this in terms of live births will obviously take many years to accumulate.

Meanwhile, we have illustrated how recent scientific advances should already be altering clinician perceptions. We have also sought to support clinicians managing uncertainties in the evidence base, with reference both to physiologic first principles and to informative data arising from other relevant patient groups. Finally, we would emphasise that men and women presenting in advanced adult life with absent puberty cannot simply be 'shoe horned' into paediatric treatment algorithms.

\section{Declaration of interest}

Dr L Dunkel participated in a symposium on delayed puberty, sponsored by Sandoz, at the 2011 Annual Meeting of the European Society of Paediatric Endocrinology. Dr R Quinton has no relevant disclosures to make during the past 3 years.

\section{Funding}

Both Dr L Dunkel and Dr R Quinton are members of an EU-funded network dedicated to fostering patient engagement, optimising clinical management and furthering collaborative research across Europe in the field of hypogonadotrophic hypogonadism: www.gnrhnetwork.eu.

\section{References}

1 Marshall WA \& Tanner JM. Variations in pattern of pubertal changes in girls. Archives of Disease in Childhood 196944 291-303. (doi:10.1136/ adc. 44.235.291)

2 Marshall WA \& Tanner JM. Variations in the pattern of pubertal changes in boys. Archives of Disease in Childhood 197045 13-23. (doi:10.1136/adc.45.239.13)

3 Marshall WA \& Tanner JM. Growth and physiological development during adolescence. Annual Review of Medicine 196819 283-300. (doi:10.1146/annurev.me.19.020168.001435)

4 Palmert MR \& Dunkel L. Clinical practice. Delayed puberty. New England Journal of Medicine 2012366 443-453. (doi:10.1056/ NEJMcp1109290)

5 Sorensen K, Aksglaede L, Petersen JH \& Juul A. Recent changes in pubertal timing in healthy Danish boys: associations with body mass index. Journal of Clinical Endocrinology and Metabolism 201095 263-270. (doi:10.1210/jc.2009-1478)

6 Sorensen K, Mouritsen A, Aksglaede L, Hagen CP, Mogensen SS \& Juul A. Recent secular trends in pubertal timing: implications for evaluation and diagnosis of precocious puberty. Hormone Research in Paediatrics 201277 137-145. (doi:10.1159/000336325)

7 Wu T, Mendola P \& Buck GM. Ethnic differences in the presence of secondary sex characteristics and menarche among US girls: the Third National Health and Nutrition Examination Survey, 1988-1994. Pediatrics 2002110 752-757. (doi:10.1542/peds.110.4.752)

8 Sun SS, Schubert CM, Chumlea WC, Roche AF, Kulin HE, Lee PA, Himes JH \& Ryan AS. National estimates of the timing of sexual 
maturation and racial differences among US children. Pediatrics 2002 110 911-919. (doi:10.1542/peds.110.5.911)

9 Sedlmeyer IL \& Palmert MR. Delayed puberty: analysis of a large case series from an academic center. Journal of Clinical Endocrinology and Metabolism 200287 1613-1620. (doi:10.1210/jcem.87.4.8395)

10 Wehkalampi K, Silventoinen K, Kaprio J, Dick DM, Rose RJ, Pulkkinen L \& Dunkel L. Genetic and environmental influences on pubertal timing assessed by height growth. American Journal of Human Biology 200820 417-423. (doi:10.1002/ajhb.20748)

11 Wehkalampi K, Widen E, Laine T, Palotie A \& Dunkel L. Patterns of inheritance of constitutional delay of growth and puberty in families of adolescent girls and boys referred to specialist pediatric care. Journal of Clinical Endocrinology and Metabolism 200893 723-728. (doi:10.1210/ jc.2007-1786)

12 Sedlmeyer IL, Hirschhorn JN \& Palmert MR. Pedigree analysis of constitutional delay of growth and maturation: determination of familial aggregation and inheritance patterns. Journal of Clinical Endocrinology and Metabolism 200287 5581-5586. (doi:10.1210/jc.2002-020862)

13 Wehkalampi K, Vangonen K, Laine T \& Dunkel L. Progressive reduction of relative height in childhood predicts adult stature below target height in boys with constitutional delay of growth and puberty. Hormone Research 200768 99-104. (doi:10.1159/000101011)

14 Dunkel L, Alfthan H, Stenman UH, Tapanainen P \& Perheentupa J. Pulsatile secretion of LH and FSH in prepubertal and early pubertal boys revealed by ultrasensitive time-resolved immunofluorometric assays. Pediatric Research 199027 215-219. (doi:10.1203/00006450199003000-00003)

15 Dunkel L \& Huhtaniemi I. Abnormal prolactin secretion in prepubertal boys with hypogonadotrophic hypogonadism - possible involvement in regulation of testicular steroidogenesis. International Journal of Andrology 19858 385-392. (doi:10.1111/j.1365-2605.1985.tb00851.x)

16 Dunkel L, Perheentupa J, Virtanen M \& Maenpaa J. Gonadotropinreleasing hormone test and human chorionic gonadotropin test in the diagnosis of gonadotropin deficiency in prepubertal boys. Journal of Pediatrics 1985107 388-392. (doi:10.1016/S0022-3476(85)80512-6)

17 Dunkel L, Perheentupa J \& Sorva R. Single versus repeated dose human chorionic gonadotropin stimulation in the differential diagnosis of hypogonadotropic hypogonadism. Journal of Clinical Endocrinology and Metabolism 198560 333-337. (doi:10.1210/jcem-60-2-333)

18 Dunkel L, Perheentupa J, Virtanen M \& Maenpaa J. GnRH and HCG tests are both necessary in differential diagnosis of male delayed puberty. American Journal of Diseases of Children 1985139 494-498.

19 Segal TY, Mehta A, Anazodo A, Hindmarsh PC \& Dattani MT. Role of gonadotropin-releasing hormone and human chorionic gonadotropin stimulation tests in differentiating patients with hypogonadotropic hypogonadism from those with constitutional delay of growth and puberty. Journal of Clinical Endocrinology and Metabolism 200994 780-785. (doi:10.1210/jc.2008-0302)

20 Demir A, Voutilainen R, Juul A, Dunkel L, Alfthan H, Skakkebaek NE \& Stenman UH. Increase in first morning voided urinary luteinizing hormone levels precedes the physical onset of puberty. Journal of Clinical Endocrinology and Metabolism 199681 2963-2967. (doi:10.1210/ jcem.81.8.8768859)

21 Coutant R, Biette-Demeneix E, Bouvattier C, Bouhours-Nouet N, Gatelais F, Dufresne S, Rouleau S \& Lahlou N. Baseline inhibin B and anti-Mullerian hormone measurements for diagnosis of hypogonadotropic hypogonadism $(\mathrm{HH})$ in boys with delayed puberty. Journal of Clinical Endocrinology and Metabolism 201095 5225-5232. (doi:10.1210/jc.2010-1535)

22 Quinton R, Cheow HK, Tymms DJ, Bouloux PM, Wu FC \& Jacobs HS. Kallmann's syndrome: is it always for life? Clinical Endocrinology 1999 50 481-485. (doi:10.1046/j.1365-2265.1999.00708.x)

23 Raivio T, Falardeau J, Dwyer A, Quinton R, Hayes FJ, Hughes VA, Cole LW, Pearce SH, Lee H, Boepple P et al. Reversal of idiopathic hypogonadotropic hypogonadism. New England Journal of Medicine 2007357 863-873. (doi:10.1056/NEJMoa066494)
24 Adulwahid NA, Armar NA, Morris DV, Adams J \& Jacobs HS. Diagnostic tests with luteinising hormone releasing hormone should be abandoned. BMJ 1985291 1471-1472. (doi:10.1136/bmj.291.6507.1471)

25 Doty RL, Shaman P \& Dann M. Development of the University of Pennsylvania Smell Identification Test: a standardized microencapsulated test of olfactory function. Physiology \& Behavior 198432 489-502. (doi:10.1016/0031-9384(84)90269-5)

26 Lewkowitz-Shpuntoff HM, Hughes VA, Plummer L, Au MG, Doty RL, Seminara SB, Chan YM, Pitteloud N, Crowley WF Jr \& Balasubramanian R. Olfactory phenotypic spectrum in idiopathic hypogonadotropic hypogonadism: pathophysiological and genetic implications. Journal of Clinical Endocrinology and Metabolism 201297 E136-E144. (doi:10.1210/jc.2011-2041)

27 Bhasin S, Cunningham GR, Hayes FJ, Matsumoto AM, Snyder PJ, Swerdloff RS, Montori VM \& Task Force ES. Testosterone therapy in men with androgen deficiency syndromes: an Endocrine Society clinical practice guideline. Journal of Clinical Endocrinology and Metabolism 2010 95 2536-2559. (doi:10.1210/jc.2009-2354)

28 Caronia LM, Martin C, Welt CK, Sykiotis GP, Quinton R, Thambundit A, Avbelj M, Dhruvakumar S, Plummer L, Hughes VA et al. A genetic basis for functional hypothalamic amenorrhea. New England Journal of Medicine 2011364 215-225. (doi:10.1056/NEJMoa0911064)

29 Smith N \& Quinton R. Kallmann syndrome. BMJ 2012345 e6971. (doi:10.1136/bmj.e6971)

30 Donaldson MD, Gault EJ, Tan KW \& Dunger DB. Optimising management in Turner syndrome: from infancy to adult transfer. Archives of Disease in Childhood 200691 513-520. (doi:10.1136/adc.2003.035907)

31 Albanese A \& Stanhope R. Predictive factors in the determination of final height in boys with constitutional delay of growth and puberty. Journal of Pediatrics 1995126 545-550. (doi:10.1016/S0022-3476(95)70347-0)

32 Richman RA \& Kirsch LR. Testosterone treatment in adolescent boys with constitutional delay in growth and development. New England Journal of Medicine 1988319 1563-1567. (doi:10.1056/NEJM198812153192402)

33 Rosenfeld RG, Northcraft GB \& Hintz RL. A prospective, randomized study of testosterone treatment of constitutional delay of growth and development in male adolescents. Pediatrics 198269 681-687.

34 Rosenfield RL. Clinical review 6: diagnosis and management of delayed puberty. Journal of Clinical Endocrinology and Metabolism $1990 \mathbf{7 0}$ 559-562. (doi:10.1210/jcem-70-3-559)

35 Soliman AT, Khadir MM \& Asfour M. Testosterone treatment in adolescent boys with constitutional delay of growth and development. Metabolism: Clinical and Experimental 199544 1013-1015. (doi:10.1016/ 0026-0495(95)90098-5)

36 Bondy CA. Care of girls and women with Turner syndrome: a guideline of the Turner Syndrome Study Group. Journal of Clinical Endocrinology and Metabolism 200792 10-25. (doi:10.1210/jc.2006-1374)

37 Carel JC, Elie C, Ecosse E, Tauber M, Leger J, Cabrol S, Nicolino M, Brauner R, Chaussain JL \& Coste J. Self-esteem and social adjustment in young women with Turner syndrome-influence of pubertal management and sexuality: population-based cohort study. Journal of Clinical Endocrinology and Metabolism 200691 2972-2979. (doi:10.1210/jc.2005-2652)

38 Conte FA, Grumbach MM \& Kaplan SL. A diphasic pattern of gonadotropin secretion in patients with the syndrome of gonadal dysgenesis. Journal of Clinical Endocrinology and Metabolism 197540 670-674. (doi:10.1210/jcem-40-4-670)

39 Cutler GB Jr. The role of estrogen in bone growth and maturation during childhood and adolescence. Journal of Steroid Biochemistry and Molecular Biology 199761 141-144. (doi:10.1016/S09600760(97)80005-2)

40 Ross JL, Kushner H \& Roeltgen DP. Developmental changes in motor function in girls with Turner syndrome. Pediatric Neurology 199615 317-322. (doi:10.1016/S0887-8994(96)00227-5)

41 Ross JL, Roeltgen D, Feuillan P, Kushner H \& Cutler GB Jr. Effects of estrogen on nonverbal processing speed and motor function in girls with Turner's syndrome. Journal of Clinical Endocrinology and Metabolism 199883 3198-3204. (doi:10.1210/jcem.83.9.5087) 
42 Saenger P, Wikland KA, Conway GS, Davenport M, Gravholt $\mathrm{CH}$, Hintz R, Hovatta O, Hultcrantz M, Landin-Wilhelmsen K, Lin A et al. Recommendations for the diagnosis and management of Turner syndrome. Journal of Clinical Endocrinology and Metabolism 200186 3061-3069. (doi:10.1210/jcem.86.7.7683)

43 Ross JL, Quigley CA, Cao D, Feuillan P, Kowal K, Chipman JJ \& Cutler GB Jr. Growth hormone plus childhood low-dose estrogen in Turner's syndrome. New England Journal of Medicine 2011364 1230-1242. (doi:10.1056/NEJMoa1005669)

44 Snajderova M, Mardesic T, Lebl J, Gerzova H, Teslik L \& Zapletalova J. The uterine length in women with Turner syndrome reflects the postmenarcheal daily estrogen dose. Hormone Research 200360 198-204. (doi:10.1159/000073233)

45 Hero M, Norjavaara E \& Dunkel L. Inhibition of estrogen biosynthesis with a potent aromatase inhibitor increases predicted adult height in boys with idiopathic short stature: a randomized controlled trial. Journal of Clinical Endocrinology and Metabolism 200590 6396-6402. (doi:10.1210/jc.2005-1392)

46 Wickman S, Sipila I, Ankarberg-Lindgren C, Norjavaara E \& Dunkel L. A specific aromatase inhibitor and potential increase in adult height in boys with delayed puberty: a randomised controlled trial. Lancet 2001357 1743-1748. (doi:10.1016/S0140-6736(00)04895-9)

47 Hero M, Toiviainen-Salo S, Wickman S, Makitie O \& Dunkel L. Vertebral morphology in aromatase inhibitor-treated males with idiopathic short stature or constitutional delay of puberty. Journal of Bone and Mineral Research 201025 1536-1543. (doi:10.1002/jbmr.56)

48 Phelan N, Conway SH, Llahana S \& Conway GS. Quantification of the adverse effect of ethinylestradiol containing oral contraceptive pills when used in conjunction with growth hormone replacement in routine practice. Clinical Endocrinology 201276 729-733. (doi:10.1111/ j.1365-2265.2011.04277.x)

49 van der Klaauw AA, Biermasz NR, Zelissen PM, Pereira AM, Lentjes EG, Smit JW, van Thiel SW, Romijn JA \& Roelfsema F. Administration route-dependent effects of estrogens on IGF-I levels during fixed GH replacement in women with hypopituitarism. European Journal of Endocrinology 2007157 709-716. (doi:10.1530/EJE-07-0412)

50 van Kesteren PJ, Asscheman H, Megens JA \& Gooren LJ. Mortality and morbidity in transsexual subjects treated with cross-sex hormones. Clinical Endocrinology 199747 337-342. (doi:10.1046/j.1365-2265.1997.2601068.x)

51 Seal LJ, Franklin S, Richards C, Shishkareva A, Sinclaire C \& Barrett J. Predictive markers for mammoplasty and a comparison of side effect profiles in transwomen taking various hormonal regimens. Journal of Clinical Endocrinology and Metabolism 201297 4422-4428. (doi:10.1210/ jc.2012-2030)

52 Asscheman H, Giltay EJ, Megens JA, de Ronde WP, van Trotsenburg MA \& Gooren LJ. A long-term follow-up study of mortality in transsexuals receiving treatment with cross-sex hormones. European Journal of Endocrinology 2011164 635-642. (doi:10.1530/EJE-10-1038)

53 Scarabin PY, Alhenc-Gelas M, Plu-Bureau G, Taisne P, Agher R \& Aiach M. Effects of oral and transdermal estrogen/progesterone regimens on blood coagulation and fibrinolysis in postmenopausal women. A randomized controlled trial. Arteriosclerosis, Thrombosis, and Vascular Biology 199717 3071-3078. (doi:10.1161/01.ATV.17.11.3071)

54 Adami S, Rossini M, Zamberlan N, Bertoldo F, Dorizzi R \& Lo Cascio V. Long-term effects of transdermal and oral estrogens on serum lipids and lipoproteins in postmenopausal women. Maturitas 199317 191-196. (doi:10.1016/0378-5122(93)90046-K)

55 Pitteloud N, Hayes FJ, Boepple PA, DeCruz S, Seminara SB, MacLaughlin DT \& Crowley WF Jr. The role of prior pubertal development, biochemical markers of testicular maturation, and genetics in elucidating the phenotypic heterogeneity of idiopathic hypogonadotropic hypogonadism. Journal of Clinical Endocrinology and Metabolism 200287 152-160. (doi:10.1210/jcem.87.1.8131)

56 Pitteloud N, Hayes FJ, Dwyer A, Boepple PA, Lee H \& Crowley WF Jr. Predictors of outcome of long-term GnRH therapy in men with idiopathic hypogonadotropic hypogonadism. Journal of Clinical Endocrinology and Metabolism 200287 4128-4136. (doi:10.1210/jc.2002-020518)

57 Warne DW, Decosterd G, Okada H, Yano Y, Koide N \& Howles CM. A combined analysis of data to identify predictive factors for spermatogenesis in men with hypogonadotropic hypogonadism treated with recombinant human follicle-stimulating hormone and human chorionic gonadotropin. Fertility and Sterility 200992 594-604. (doi:10.1016/j.fertnstert.2008.07.1720)

58 Liu PY, Baker HW, Jayadev V, Zacharin M, Conway AJ \& Handelsman DJ. Induction of spermatogenesis and fertility during gonadotropin treatment of gonadotropin-deficient infertile men: predictors of fertility outcome. Journal of Clinical Endocrinology and Metabolism 200994 801-808. (doi:10.1210/jc.2008-1648)

59 Zacharin M, Sabin MA, Nair VV \& Dabadghao P. Addition of recombinant follicle-stimulating hormone to human chorionic gonadotropin treatment in adolescents and young adults with hypogonadotropic hypogonadism promotes normal testicular growth and may promote early spermatogenesis. Fertility and Sterility 201298 836-842. (doi:10.1016/j.fertnstert.2012.06.022)

60 Barrio R, de Luis D, Alonso M, Lamas A \& Moreno JC. Induction of puberty with human chorionic gonadotropin and follicle-stimulating hormone in adolescent males with hypogonadotropic hypogonadism. Fertility and Sterility 199971 244-248. (doi:10.1016/S0015-0282(98)00450-6)

61 Dwyer AA, Sykiotis GP, Hayes FJ, Boepple PA, Lee H, Loughlin KR, Dym M, Sluss PM, Crowley WF Jr \& Pitteloud N. Trial of recombinant follicle-stimulating hormone pretreatment for GnRH-induced fertility in patients with congenital hypogonadotropic hypogonadism. Journal of Clinical Endocrinology and Metabolism 201398 E1790-E1795. (doi:10.1210/jc.2013-2518)

62 Santhakumar A, Miller M \& Quinton R. Pubertal induction in adult males with isolated hypogonadotropic hypogonadism using longacting intramuscular testosterone undecanoate 1-g depot (Nebido). Clinical Endocrinology 201480 155-157. (doi:10.1111/cen.12160)

63 Mehta A, Bolyakov A, Roosma J, Schlegel PN \& Paduch DA. Successful testicular sperm retrieval in adolescents with Klinefelter syndrome treated with at least 1 year of topical testosterone and aromatase inhibitor. Fertility and Sterility 2013100 970-974. (doi:10.1016/ j.fertnstert.2013.06.010)

64 Rives N, Milazzo JP, Perdrix A, Castanet M, Joly-Helas G, Sibert L, Bironneau A, Way A \& Mace B. The feasibility of fertility preservation in adolescents with Klinefelter syndrome. Human Reproduction 201328 1468-1479. (doi:10.1093/humrep/det084)

65 Gilsanz V, Chalfant J, Kalkwarf H, Zemel B, Lappe J, Oberfield S, Shepherd J, Wren T \& Winer K. Age at onset of puberty predicts bone mass in young adulthood. Journal of Pediatrics 2011158 100-105, 105 e101-102. (doi:10.1016/j.jpeds.2010.06.054)

66 El-Shawarby SA, Sharif F, Conway G, Serhal P \& Davies M. Oocyte cryopreservation after controlled ovarian hyperstimulation in mosaic Turner syndrome: another fertility preservation option in a dedicated UK clinic. BJOG: an International Journal of Obstetrics and Gynaecology 2010117 234-237. (doi:10.1111/j.1471-0528.2009.02422.x)

67 Wickman S \& Dunkel L. Inhibition of P450 aromatase enhances gonadotropin secretion in early and midpubertal boys: evidence for a pituitary site of action of endogenous E. Journal of Clinical Endocrinology and Metabolism 200186 4887-4894. (doi:10.1210/jcem.86.10.7927)

Received 1 November 2013

Revised version received 12 February 2014

Accepted 14 February 2014 